\title{
Sujeito, desejo e gozo: para uma terapia da concepção de linguagem de Lacan
}

\author{
João José R. L. Almeida \\ Universidade Estadual do Oeste do Paraná
}

\begin{abstract}
resumo Focado num trecho de "Position de L'inconscient", este artigo faz a descrição gramatical das figuras de sujeito e de linguagem ali empregadas. A intenção é exclusivamente terapêutica - não se trata de propor novas teses, mas provocar o olhar para aspectos negligenciados da prática psicanalítica.
\end{abstract}

palavras-chave Lacan - Wittgenstein - Linguagem - Subjetividade.

Wittgenstein registrou em suas Investigações que "Toda uma nuvem de filosofia se condensa numa gota de gramática" (WITTGENSTEIN, 1958, parte II, p. 222). O que quer dizer essa frase, senão que uma "figura" instalada num jogo de linguagem pode impor sérios obstáculos à ação? Uma "figura", no sentido exposto nas Investigações Filosóficas, é o rosto ou a fisionomia (WITTGENSTEIN, 1958, \ 228) da prática de uma determinada ação. As "regras da vida estão vestidas de figuras" (WITTGENSTEIN, 1998, p. 34). Uma ordem a ser executada, por exemplo, deve ser feita segundo uma figura (WITTGENSTEIN, 1958, \ 519), assim como a pintura de uma cena ou a execução de uma função matemática. As figuras, porém, carregam consigo sempre a possibilidade do surgimento de uma interpretação confusa; isto é, assim como é factível ver nos traços de alguém a fisionomia de outro, existe na figura a possibilidade do surgimento de uma interpretação entrelaçada com uma atividade em relação à qual aquela apresenta uma desarticulação (WITTGENSTEIN, 1958, SS 228, 300-301). Mas esse não é todo o

Recebido em 29 de novembro de 2005. Aceito em 03 de fevereiro de 2006.

doispontos, Curitiba, São Carlos, vol. 3, n. 1, p.193-209, abril, 2006 
problema, pois o que realmente parece ser perturbador é que a obnubilação torna-se crônica, já que as figuras são dotadas de uma força compulsiva que nos faz repetir inflexivelmente o mesmo padrão de comportamento. Uma gramática é, de fato, um procedimento que se repete indefinidamente porque impõe uma vontade segundo moldes socialmente estabelecidos. Essa vontade afigurada imprime uma direção para o pensamento nos trilhos da gramática. Quando neste quadro surgem interpretações equivocadas, as representações são tomadas de maneira especial e, particularmente, fechada, como se, por exemplo, abrigassem uma espécie de mistério profundo, ou uma espécie de fascínio ou deslumbramento com relação a uma suposta realidade que não seria mais do que mera "ilusão gramatical" (WITTGENSTEIN, 1958, \ 110). Podemos, portanto, chegar a interpretar muito mal as nossas expressões cotidianas e tirarmos delas "as mais estranhas conclusões" (WITTGENSTEIN, 1958, \ 194). Wittgenstein dizia o seguinte com relação a sua antiga crença na existência de uma forma ideal de linguagem: "Uma figura nos havia aprisionado. E não podíamos escapar, porque ela estava na nossa linguagem, e a linguagem parecia reiterá-la inexoravelmente para nós” (WITTGENSTEIN, 1958, \115). A maneira que the pareceu mais apropriada para evitar o dogmatismo foi a de não tentar encontrar na linguagem uma forma ideal, mas observar como podemos utilizá-la de várias maneiras para dizer o que precisamos.

Neste artigo pretendo valer-me de algumas das reflexões de Wittgenstein 1 e caminhar na direção de uma terapia de certas figuras criadas pela concepção de linguagem de Jacques Lacan. A finalidade dessa terapia não é a de encontrar solução para eventuais problemas conceituais da teoria lacaniana. A terapia gramatical não pretende prescrever nem sugerir absolutamente nada ao paciente. Ao contrário, ela deixa tudo exatamente como está (WITTGENSTEIN, 1958, \ 124). A única pretensão é a de que as intervenções possam dissolver o que aparece como confusão, o que se nos afigura como um mistério insondável, profundo ou fascinante, o que se nos propõe como uma estrutura determinada por detrás das palavras, o que nos parece ser inelutável e ter o caráter de necessidade. $\mathrm{O}$ trabalho terapêutico pode até mesmo valer-se de um certo vigor, configurar-se como uma "luta contra o feitiço do nosso entendimento pela linguagem” (WITTGENSTEIN, 1958, \109); 
mas a sua ação não é a de usar a força contra o paciente e converter o enfermo a uma nova tese, supostamente mais salvífica, ou modificar in totum o estado da arte. O método terapêutico recomenda apenas usar de artifícios para chamar a atenção do doente para a sua maneira habitual de considerar certos conceitos, recomenda inclusive encontrar e inventar (finden und erfinden) elementos para que ele possa enxergar suas conexões conceituais (WITTGENSTEIN, 1958, \122). Por isso, mais que ao acerto da descrição, a intervenção terapêutica preocupa-se em agir sobre o olhar a fim de ampliar a visão pela multiplicação dos exemplos, pela variação dos aspectos e pela iluminação das linhas de encaixe; o que permite, em conseqüência, à razão a possibilidade de pensar por si mesma outras formas de articulação dos problemas. Dito de outra maneira, a única pretensão é a cura do dogmatismo pela garantia da autonomia da primeira pessoa. Isso significa "devolver as palavras do seu uso metafísico para o ordinário” (WITTGENSTEIN, 1958, \116). Mediante o esclarecimento das ligações conceituais das passagens enevoadas da teoria psicanalítica uma prática pode livrar-se de confusões gramaticais. Acredito que, pelo método da visão panorâmica das pretensas questões fundamentais, é possível decompor o procedimento técnico e detectar o que ali vem contrabandeado de outras formas de vida. Nesse sentido, a descrição dos procedimentos e modos de agir da teoria de Lacan, a localização das suas fontes, dos seus pressupostos tácitos e das suas finalidades, pode fazer com que a linguagem "volte ao solo áspero" (WITTGENSTEIN, 1958, 』 107). Esses são, no entanto, apenas os primeiros passos, um ensaio para uma tarefa que é muito mais complexa do que seria possível fazer em tão poucas páginas. Não obstante, o caminho deve ser iniciado.

Comecemos, então, por este pequeno trecho que aparece em Position de l'inconscient: "o efeito de linguagem é a causa introduzida no sujeito. Por esse efeito, ele não é causa de si, mas carrega o verme da causa que o cinde" (LACAN 1964a, p. 835). A idéia é mostrar, neste excerto, mas com a ajuda do seu contexto mais amplo e de alguns outros textos, como Lacan prepara os encaixes das suas articulações para que as noções de "sujeito", de "desejo" e de "gozo", fundamentais para a teoria psicanalítica, pareçam sucedâneos naturais da disciplina inaugurada por Freud apesar das estratégias, sempre presentes, de excluir da teoria qualquer 
concepção de vida interior e de instituir uma disciplina metodologicamente rigorosa. Mediante a nova organização teórica, a psicanálise poderia, supostamente, abrigar sua operacionalidade própria sem comprometer-se com crenças metafísicas injustificáveis.

\section{Razões e Causas}

O primeiro passo de nossa análise consiste em observar como, no fragmento, pode ser recuperada para a psicanálise a concepção de causa $e$ efeito. A relação de causa e efeito pertence, em princípio, ao âmbito da organização da experiência. Isso significa que quem postula relações de causa e efeito supõe haver, desde logo, uma distinção entre a esfera mental (ou lingüística) organizadora da experiência, e a experiência recebida do mundo. Uma distinção, digamos assim, entre um prolongamento amorfo que está fora ou diante de nós no mundo e uma outra instância, distinta, dotada da capacidade de apor uma ordem nesse contínuo difuso e caótico com o qual nos defrontamos. Isso faz com que, também em princípio, a suposição da existência de relações de causa e efeito seja um procedimento adequado ou apropriado para teorias de caráter empírico. Melhor dizendo, para teorias cuja função é explicar o que ocorre na experiência ou no mundo, sem distanciar-se da matéria que as confronta e ocupar-se com um discurso sobre coisas que ultrapassam a percepção. Essa é uma questão de método, simplesmente. Há outras teorias que podem, legitimamente, dispensar o método empírico e passar a tratar suas questões de maneira exclusivamente especulativa; desse modo, referir-se-ão ao mundo, se for esse o caso, apenas mediante um encadeamento de motivos ou razões.

Que diferença há entre uma e outra maneiras do agir teórico? Há, basicamente, três diferenças que, pelo menos no plano ideal, devem estar assim estabelecidas: a primeira é que as teorias empíricas têm caráter contingente, e suas asserções podem ser falseadas; enquanto as teorias especulativas têm caráter lógico, e suas asserções são necessárias. A segunda diferença é que as teorias empíricas tratam de fenômenos que são recebidos como independentes do conjunto teórico que a eles se ajusta e subordina, enquanto os objetos das teorias especulativas estão fechados 
dentro do sistema. A terceira diferença é a de que na cadeia causal não pode haver uma causa primeira de todas as causas que seja, ela também, uma causa: a idéia de causa sui, se postulada, seria estranha à relação de causa e efeito, e teria que ser aceita como uma exceção à regra, isto é, explicar-se-ia somente como uma razão ou motivo. Dessa maneira, a cadeia causal, a rigor, tem que ser suposta como potencialmente infinita e interligada no mundo empírico; o mesmo não vige para os objetos das teorias especulativas.

Se a psicanálise recupera a idéia de causa e efeito, ela pode estar querendo dizer duas coisas mutuamente exclusivas: ou está afirmando que a matéria de que trata é empírica, e ela é uma teoria sobre fatos contingentes, independentes e abertos, ou está abolindo a distinção entre linguagem e mundo e, com isso, a tradicional diferença entre causas e razões. Para o caso de Lacan, só nos resta a segunda opção.

\section{Sujeito e Estrutura}

Outro dado que aparece no trecho citado é que a relação entre causa e efeito se estabelece sobre a base da conexão entre o sujeito e a linguagem. Uma boa pista para compreendermos o que se subentende no vínculo linguagem/subjetividade é reparar que Lacan, desde a tese de 32, sempre buscou teorizar o sujeito por meio de uma estrutura. Em 32, atendendo às diretrizes politzerianas a respeito da psicologia concreta (POLITZER, 1928), Lacan considerou o sujeito com relação a uma "estrutura reacional da personalidade" que poderia explicar as causas ocasionais, eficientes e específicas da psicose paranóica (LACAN, 1932, p. 347-348); de 1938, com “Os complexos familiares", até 1953, prevaleceu a estrutura da imago, que, na suposição de um corpo despedaçado originário, explicava a neurose e a psicose pelo processo de identificação alienada no outro mediante a antecipação da imagem de um corpo próprio (LACAN, 1949); de 1953 até 1956, estabeleceu-se a estrutura simbólica na qual o sujeito, por um ideal de eu, se reconhecia como um eu ideal necessariamente alienado (LACAN, 1954); de 1957 até 1964, a estrutura da linguagem, entendida como as operações diferenciais e articuladas da cadeia significante, serviu como modelo para a evolução dos 
principais conceitos da psicanálise lacaniana: o inconsciente, a transferência, o objeto $a$ e a pulsão (LACAN, 1964b); em 1969, aparecem as estruturas dos discursos, nas quais o sujeito, em diferentes modalidades, perfaz quatro tipos de laços sociais junto com as demais figuras dessa estrutura (o Senhor, o saber e o gozo), nos quais pode ocupar as posições do desejo, do outro, da perda e da verdade (LACAN, 1970, p. 113-114); e, finalmente, em 1972, é a topologia dos nós borromeanos a estrutura pela qual as leis do inconsciente determinam o sujeito (LACAN, 1972).

O que há de comum em todas essas fases, e de peculiar nesse vínculo estendido entre o sujeito e a estrutura, é que existe sempre uma implicação mútua entre as partes: o sujeito é inseparável da estrutura não se pode conceber a estrutura sem o sujeito, nem o sujeito sem a estrutura. De fato, sem pressupor uma "coalescência" entre as duas instâncias (LACAN, 1969, lição de 18/06/1969), o discurso causal assumido na teoria substancializaria de imediato a contraparte estrutural. A estrutura teria que ser tão rígida quanto a madeira maciça da mesa sobre a qual as bolas de bilhar rolam e ricocheteiam. Não haveria, por essa hipótese, como imaginar uma determinação causal senão como uma relação estabelecida entre objetos separados no tempo e no espaço. A coalescência deixaria de ser correta no argumento. No entanto, a prova da sua validade vem precisamente pelo discurso da conexão causal. Lacan, quando se refere à causalidade em nosso texto, menciona o seu caráter retroativo, nachträglich, introduzido a partir do efeito, segundo o qual "o trauma se implica no sintoma" (LACAN 1964a, p. 839). Essa maneira peculiar de estabelecer relações causais é, na realidade, não a descrição de uma relação empírica entre partes estanques do mundo, mas um artifício de cosimento, a construção de uma rede pelas linhas de uma trama previamente dada. Aí está a estrutura: um drama escrito sobre um roteiro pré-moldado.

O tempo de Lacan segue o mesmo modelo estrutural. Ele não é o tempo cronológico, puramente objetivo, mas o que chama de "tempo lógico", dessubjetivado por duas escansões e subjetivado numa asserção de certeza antecipada (LACAN, 1945). Esse tempo e esse espaço são, naturalmente, efeitos da estrutura, que, sendo impessoal e, portanto, não-subjetiva, dá ocasião teórica para conceituar a subjetividade, seu espaço e seu tempo. O que temos aqui, portanto, é que, mais que agir à 
causa de uma determinação rígida, na teoria de Lacan o sujeito age de acordo com uma estrutura ou segundo uma lógica que dá guarida a uma noção de sujeito e de causalidade peculiar. Mais adiante veremos como opera essa lógica.

\section{Assimetria Entre Desejo e Gozo}

$\mathrm{Na}$ fase correspondente ao trecho que analisamos, Lacan trabalhava arduamente para diferenciar desejo de gozo. Por quê? Há duas hipóteses: a primeira, de contorno mais intelectual, é que ao final do seminário de 1958-1959 sobre as Formações do inconsciente, Lacan teria vislumbrado a necessidade teórica e clínica de diferenciar o falo simbólico $\Phi$, operador da metáfora paterna, do falo imaginário $\phi$, que provoca as respectivas ilusões de ter e ser ou perder e não-ser. Acerca dessa dinâmica, nosso autor já havia diferenciado as posições subjetivas de frustração (imaginária), privação (real) e castração (simbólica) em relação ao objeto. A partir de um certo momento, contudo, Lacan deslocou a ênfase do sujeito para o próprio objeto, parte integrante da dinâmica do comportamento inconsciente para o qual ele não havia, até ali, concentrado seus esforços teóricos. Desde o seminário sobre O desejo e sua interpretação, em 1959, ele passou a tratar de um falo negativo, um falo sempre ausente tanto para o homem quanto para a mulher (LACAN, 1964c, p. 852), e, conseqüentemente, de um tipo de objeto não-especular. A diferença entre desejo e gozo acompanha esses deslocamentos, ficando o conceito de desejo como um aspecto simbólico da dinâmica do inconsciente (a castração cria a falta que institui o desejo ou a lei), portanto um aspecto mais pertinente ao sujeito que ao objeto, e o gozo como o seu ponto de vista real, mais pertinente ao objeto faltante que ao sujeito.

A segunda hipótese, de contornos mais práticos, seria estritamente clínica. Desde 1953, a clínica lacaniana vinha operando nos intervalos entre o eu ideal e o ideal de eu, com o propósito de criar condições para que o paciente vislumbrasse a possibilidade de trocar a sua posição passiva de desejo de reconhecimento para uma posição ativa de reconhecimento do desejo. Essas intervenções clínicas, no entanto, pareciam funcionar apenas nos registros do imaginário e do simbólico. Paralela- 
mente, Lacan já reconhecia o papel da negatividade dialética quando tratava da ausência ou da separação como fundadora do simbólico; mas a clínica ainda prescindia de uma forma de atuação na qual esse tempo mítico do vazio ou uma vivência segundo uma perda pudesse ser ativado. O conceito de gozo proporciona essa nova condição, já que o analista, na posição de objeto, pode receber na transferência tanto a pulsão de morte quanto a compulsão à repetição como manifestações de gozo e não de desejo, provenientes do real, e não mais do simbólico ou do imaginário. Um sintoma, na realidade, é um gozo. Melhor dizendo, é a expressão das "desventuras do desejo nas sebes do gozo" (LACAN, 1964c, p. 853). A neurose passa a ser tratada, então, como uma recusa do sacrifício da castração para o gozo do Outro. Na clínica da neurose, é o gozo que precisa ser recusado e a lei do desejo, invertida (cf. LACAN, 1960, p. 826-827).

$\mathrm{O}$ efeito desses deslocamentos, entretanto, foi um buraco cavado na estrutura a fim de que naquele vazio se acomodasse um objeto suposto no desejo do Outro. Pelo que, vê-se, a estrutura não é mais consistente apenas aparenta sê-lo. Nesse vazio estrutural, o sujeito pode acomodar-se e fazer as vezes de objeto do desejo do outro, ou pode desalojar-se e deixar cair a posse desse objeto e assumir o papel de sujeito. Assim, abrese uma nova forma de vínculo entre o sujeito e a estrutura: a coalescência pelo vazio. O sujeito é, ele mesmo, também estruturalmente dividido, já que constitucionalmente o desejo lhe vem do Outro e o gozo vem da Coisa (1964c, p. 853). A própria pulsão o divide com relação ao desejo, e essa estrutura, agora denominada como "fantasia", ficou consignada na fórmula "sujeito barrado punção de $a$ ": \$ڤ $\$$

\section{A Lógica do Não-Todo}

Retomo agora a questão da lógica da teoria de Lacan. Concordo com Colette Soler em que há uma lógica no pensamento de Lacan, e cujas fórmulas paradoxais referem-se, em realidade, aos sintomas, ou refletem o ajustamento da racionalidade à especificidade da psicanálise (SOLER, 2003, p. 86). Na lição de 19/06/1957 do seminário sobre As relações de objeto, Lacan, de fato, declara que a lógica do inconsciente não deve ser 
tomada como a lógica habitual, ela seria como uma "lógica de borracha", assim como a topologia seria como uma "geometria de borracha" (1957). Nada disso quer dizer, porém, que a teoria tenha que ser conformada, também ela, por uma lógica distorcida. A teoria, como teoria do inconsciente, não é o inconsciente, é um discurso de segunda ordem e trata dele obedecendo à lógica habitual. Por isso é que fórmulas tais como "A mulher não existe", "não há relação sexual", "o significante representa o sujeito para outro significante" ou as "fórmulas da sexuação", que aparecem no Seminário $X X$, pertencem à lógica da subjetividade ou representam a estrutura segundo a qual age o sujeito. A teoria, porém, faz com que tais fórmulas sejam perfeitamente inteligíveis à luz do fundo de racionalidade sobre o qual estão constituídas.

Qual seria esse "fundo de racionalidade" pelo qual se molda a teoria lacaniana? Já vimos que Lacan desconsidera a distinção entre linguagem e mundo porque a sua idéia de "causalidade" não é empírica, é racional. $\mathrm{O}$ que temos que fazer agora é desvelar os operadores dessa racionalidade. Esses certamente estão contidos na sua concepção de linguagem, para cuja compreensão recorrerei a certos tipos ideais que não pretendo que sejam precisos, mas que emprestem coerência ao argumento (HACKING, 1975, p. 18-24).

Há concepções de linguagem referenciais, comportamentais e idealistas. O que chamo de "concepção referencial" da linguagem são as orientações que pretendem resolver o problema do "mundo externo" e da sua "percepção" na questão do "significado", compreendido como correspondência entre linguagem e mundo; o melhor modelo seria o positivismo lógico iniciado pelo Círculo de Viena. Por "concepção comportamental" entendo a visão que propõe que as sentenças, e, por conseguinte, os sentidos, não se separam de outras formas de manifestações vivenciais como a ação ou o uso, nem do contexto cultural e valorativo no qual essas manifestações ocorrem; seu paradigma seriam as Investigações Filosóficas de Wittgenstein. Toda a disposição filosófica, porém, de igualar o perceptum às sentenças, desconsiderando completamente o aspecto causal da referência como fator extralingüístico, denomino como "concepção idealista da linguagem”. A realidade, aqui, seria não mais do que um modo de determinação lingüística, a usual conexão entre mundo externo e linguagem, outra modulação lingüística, e a relação entre a 
linguagem e a subjetividade, ainda outra forma de modulação da linguagem. A linguagem torna-se, portanto, a própria totalidade, e ela mesma se encarrega de subdividir-se em "dentro" e "fora", ou "subjetivo" e "objetivo". Desta forma, essa posição nos lembraria o idealismo de Berkeley, no qual "ser é ser percebido" ou "nada existiria senão na nossa mente" (no lugar de "mente" colocaríamos, então, as ordens da linguagem). A teoria lacaniana corresponde a uma concepção idealista da linguagem. Esse é o modelo segundo a qual ela opera.

Não obstante, se recolhermos da filosofia alguns modelos clássicos de pensamento idealista, nenhum deles terá o padrão de racionalidade que abriga a teoria de Lacan. Se olharmos para Platão, Berkeley, Fichte, Schopenhauer, e até mesmo, para a grande surpresa de quase todo mundo, para Hegel, não veremos ali o mesmo desenho lógico. Todas essas são filosofias de "totalidades", é certo, mas Lacan, ao contrário, defende o "não-todo". Sua totalidade é, digamos assim, negativa.

Há um livro de Slavoj Zizek, O mais sublime dos histéricos, Hegel com Lacan (1991), no qual o autor nos diz que "Lacan 'não sabia onde era hegeliano', pois sua leitura de Hegel inscreveu-se na tradição de Kojève e Hyppolite" (ZIZEK, 1991, p. 15). Apesar dessas influências, ele defende que Lacan era essencialmente hegeliano, sobretudo na última etapa dos seus ensinamentos, isto é, na lógica do não-todo e na ênfase colocada no real e na falta do Outro. A leitura do livro, porém, nos revela precisamente o contrário: que Hegel era essencialmente lacaniano. Ocorre que todo o sistema hegeliano é lido por Zizek estritamente à luz do capítulo IV, parte A, da Fenomenologia do espírito, a luta do Senhor e do Escravo pelo reconhecimento do desejo (Lynch, 2001). A conhecida distinção entre o Espírito Subjetivo, o Espírito Objetivo e o Espírito Absoluto desaparece completamente à custa da preeminência da negatividade e da exclusão do resto do sistema. $\mathrm{O}$ anacronismo parece ser tão grande que o leitor que chega à última página descobre, para seu espanto, que também Hegel “atravessou a fantasia” (ZIZEK, 1991, p. 227).

Nesse sentido, não há porque desacreditarmos de Lacan quando ele mesmo diz que o seu uso da Fenomenologia não comporta nenhuma fidelidade ao sistema, e de que a sua Aufhebung transforma a de Hegel (LACAN, 1964a, p. 837). Essa mesma crítica a Hegel já aparecia na lição de 20/11/1963 do Seminário X (LACAN, 1963), justificada pelo recurso 
à negatividade fundamental utilizada no conceito psicanalítico de angústia. O modelo dessa totalidade negativa, desse não-todo, é mesmo o de Alexandre Kojève. No entanto, à diferença do seu mestre em Hegel, Lacan aprofundou a negatividade retirando-lhe a historicidade e patologizando o desejo (cf. ALMEIDA, 2004, cap. 2). Embora fosse ousado dizer que Lacan estaria instrumentalizando uma “ontologia negativa”, já que este nega peremptoriamente qualquer recurso a uma "ontologia" (LACAN, 1964b, lição de 29/01/1964, e 1971, lição de 21/06/1972), é inegável, pelo menos, a presença de uma lógica ou de uma racionalidade negativa inspirada em Kojève. É exatamente Kojève quem se estanca no Espírito Subjetivo, vê o homem como um "vazio ávido de conteúdo" (KOJÈVE, 1947, p. 167), e pensa o desejo como "presença de uma ausência" (KOJÈVE, 1947, p. 368).

Como funciona essa lógica? Ela atua pelo modelo de que "o universal se funda pela exceção e não pelo atributo comum” (LACAN, 1961, lição de 14/03/1962, e 1971, lição de 03/03/1972). Universalizar, generalizar, estender na forma de conjunto um atributo comum pelo qual se reconhece o elemento, é uma função realizada às custas do apagamento do traço particular e único do elemento. Ao dizer cão, ressalta Kojève, matamos o cão particular para criar o conceito (KOJÈVE, 1947, p. 372373). A lógica de Lacan hegelianamente nos ensina que devemos levar em conta não somente a instância de afirmação (o em-si), mas também a de negação (o para-si), numa dinâmica que abarca as forças mútuas, porém sem nenhuma possibilidade de reconciliação. Com Lacan é inimaginável efetuar-se uma "consciência de si". A afirmação não integra a totalidade do seu contraposto, o particular, numa negação da negação que dissolva a oposição e dê repouso ao pensamento em um novo patamar do caminho do Espírito rumo ao Absoluto. Permanece, desse modo, o real como aquilo que falta para suturar o universal, permanece a inquietação do gozo impossível na eternização do trabalho e na infinitização do desejo. Como não há reconciliação, conservamo-nos fixados na luta do Senhor e do Escravo, e segue inexaurível a combustão pelo negativo. A afirmação do universal não somente nega o particular, mas essa negação é necessária como sustentáculo do próprio discurso, que não pode se fechar numa totalidade porque essa negação está sempre presente como força desintegrante. 
Essa é a figura presente tanto na tríade real-simbólico-imaginário quanto nas fórmulas da sexuação. O real é o que fica excluído pela instituição do simbólico, mas, ao mesmo tempo, é pressuposto como a exceção que retorna para descosturar o simbólico pelo estilhaçamento do imaginário. O real é o falso pelo qual se deduz o verdadeiro, é o lugar do gozo impossível, a condição para que o corpo não despedaçado seja antecipado pelo simbólico, onde a relação sexual nos foi impossibilitada pela castração e cujo sintoma nos faz sofrer no imaginário. Por que digo que há aqui uma lógica? Porque a noção de validade lógica prescreve que não podemos considerar o antecedente verdadeiro e o conseqüente falso. No caso da teoria lacaniana, deriva-se o verdadeiro do falso, o que é logicamente correto. $\mathrm{O}$ simbólico institui-se pela perda do real. Seu sistema permite a operação de uma totalidade negativa. Uma totalidade que nunca se dá, mas que se confronta com a particularidade do sujeito, a qual, portanto, está sempre suposta como o falso do qual a pretensão de completude se deriva.

\section{Ilusões Gramaticais}

Segundo o trecho que analisamos, o sujeito é o suporte de um "verme" - é dessa maneira que Lacan qualifica a impossibilidade lingüística de integralização do particular numa coisa chamada "sujeito". O sujeito é vazio, ele está no real (LACAN, 1964a, p. 835), e a sua manifestação é uma subjetividade dividida por uma cisão causada pela lógica da linguagem. O sujeito, por isso, não é nada senão uma diferença empenhada em ocupar lugares vazios. O que podemos concluir da análise desse pequeno trecho? Podemos descrever ali pelo menos três ilusões gramaticais: a do sujeito, a da linguagem e a da sua necessidade teórica.

O que seria uma "ilusão gramatical"? A diferença entre proposições gramaticais, analíticas e empíricas pode ajudar a esclarecer o significado dessa expressão. As proposições gramaticais, embora pareçam, e até mesmo possam ser usadas como proposições analíticas ou empíricas, são, na realidade, enunciados normativos: elas estabelecem o uso e o sentido de uma prática lingüística. Isto é, não podem ser negadas sem que essa prática se desoriente e o seu sentido se perca. O que pode ser contado 
como realidade, dentro de uma forma de vida, é enunciado justamente nesse tipo de proposições. Assim, por exemplo, dizer que "esta é a minha mão", "o branco é mais claro que o preto", " $2+2=4$ ", "a palavra 'letra' tem cinco letras", "a unidade acústica ou visual reconhecida pela sua diferença em relação a outras unidades, e utilizada em associação a significados, é o significante" é, mais que descrever a experiência, organizá-la. Essas proposições estabelecem, ensinam e mantêm, pelas correções, o padrão mediante o qual uma determinada prática deve ser desempenhada, tal como o reconhecimento das partes do corpo, a classificação das cores, a regra de adição, o significado das letras, e o uso de significantes na lingüística.

A ilusão gramatical ocorre quando as proposições normativas de um jogo surgem furtivamente dentro de outro jogo, produzindo a ficção de um lance natural. Em relação ao nosso caso, pode-se afirmar que a proposição "o sujeito é a manifestação de uma cisão causada pela linguagem" é uma ilusão gramatical. Do ponto de vista prático, já presumimos no setting analítico a responsabilidade da primeira pessoa nas figuras reguladas pelo jogo da transferência. Essa norma está estabelecida pela proposição gramatical que nos ensina que aquele que fala na transferência é o paciente. O sujeito faz parte dessa prática naturalmente, adquire nessa atividade o seu sentido, espera-se, na transferência, a ocorrência de atitudes desencontradas e contraditórias como, precisamente, expressões de subjetividade. Mas o sujeito não é algo, como um objeto físico, a respeito do qual possamos fazer uma descrição ou dizer que está dividido pela linguagem, algo a respeito do qual possamos fazer a pergunta "o que é?" ou, em nosso caso, a pergunta “o que não é?”. A real coalescência aqui, a que realmente vige na prática, deveria ser a do sujeito com as suas manifestações subjetivas. Entretanto, ao separarmos um lugar vazio e falso como espaço de reserva negativo para a análise da linguagem, separamos o sujeito como um algo que "não é". Algo da subjetividade, portanto, se perde como possibilidade de expressão numa variação ampla e ilimitada de manifestações lingüísticas. A ilusão gramatical a respeito da "cisão" do sujeito como manifestação de subjetividade é uma figura proveniente do discurso empírico e instalada, sem necessidade, no jogo de linguagem da psicanálise. Essa ilusão cria uma perspectiva exclusiva dos acontecimentos, a de que haveria sempre no sujeito uma "falta a ser". 
Tampouco a linguagem, que o sujeito usa e que regula a clínica, é, em segundo lugar, uma coisa material, tal como uma faca, capaz de repartir ao meio um abacaxi. Também aqui aparece uma ilusão: não a mesma ilusão de objeto espaço-temporal, mas a de que seria possível descrever a forma lógica do comportamento irracional e do sofrimento psíquico, como se tal necessidade também existisse na clínica. Mas a pergunta acerca da "linguagem lisa"(WITTGENSTEIN, 1958, \ 107), enquanto parece adequada para a gramática das proposições analíticas atemporais, injeta-nos uma anestesia quando se dirige a fatos psicológicos. A razão é que deixamos de olhar para o que está ali diante de nós (WITTGENSTEIN, 1958, \& 126).

Em terceiro lugar, podemos tentar saber para que serve uma tal concepção de "sujeito" e de "linguagem". A clínica, com suas regras perfeitamente consolidadas na tradição, aparentemente prescinde desses acréscimos metafísicos. Podemos suspeitar de que, com isso, a teorização de Lacan esteja mais a serviço da criação de uma ciência especial da subjetividade na psicanálise (a esse respeito, ver NOBUS, 2003), do que propriamente da concretização da disciplina pelos parâmetros pragmáticos prescritos por Politzer (ver POLITZER, 1928) e já empregados por nosso autor em sua tese de 32. Seria, então, o caso de nos perguntarmos agora se a obsessão pela legitimação teórica da psicanálise não seria uma espécie de inútil desejo de reconhecimento.

Que destino daremos aos conceitos de "sujeito", "desejo" e "gozo"? Nenhum. Eles já são perfeitamente compreensíveis na clínica sem necessidade de esforço intelectual. Como diz Alberto Caeiro, há metafísica bastante em não pensar em nada. Pensar, aliás, é estar doente dos olhos.

\section{0 Projeto Terapêutico}

A causa principal das doenças filosóficas, adverte-nos Wittgenstein, é alimentar nosso pensamento com uma dieta unilateral (WITTGENSTEIN, 1958, \593). O tratamento consiste em multiplicar os exemplos e despertar a visão para outros aspectos da mesma configuração. Em nosso caso, perceber que a regra da psicanálise prescinde de teorização científica ou filosófica, fazer ver que a clínica pode funcionar perfeitamente sem 
a interposição de pesados aparatos conceituais. O próprio Lacan já comparou a psicanálise a um jogo de bridge e às negociações diplomáticas (LACAN, 1945, p. 212). O que é necessário num jogo, senão que exista uma regra clara? Na psicanálise há uma regra fundamental. Esta prescreve o jogo da transferência, a interação suficiente e necessária entre paciente e analista para que a clínica psicanalítica possa chegar a seu termo. Quanto à terapia gramatical da concepção de linguagem de Lacan, entretanto, o nosso paciente precisa perceber por si mesmo que "a principal fonte dos desentendimentos é que não temos uma visão abrangente do uso das nossas palavras" (WITTGENSTEIN, 1958, \ 122). Ele precisa ainda desatar os nós que amarram a clínica ao sobrepeso da teoria. A terapia, contudo, recomenda fortemente a paciência: a cura deve ser necessariamente lenta, já que a doença tem que seguir o seu curso natural (cf. WITTGENSTEIN, 1967, \ 382).

1 É ponto discutível se há ou não - e como - uma continuidade da teoria pictórica na filosofia de Wittgenstein após o Tractatus. Stenius (1981) pensa que sim, e Hacker (1981) se posiciona definitivamente contra. Não pretendo entrar nessa polêmica: o objetivo do presente artigo são certas figuras da concepção de linguagem de Jacques Lacan.

\section{Referências bibliográficas}

ALMEIDA, J. J. R. L. 2004. A Compulsão à Linguagem na Psicanálise: Teoria Lacaniana e Psicanálise Pragmática. Campinas. 189 páginas. Tese (Doutorado em Filosofia). Unicamp- IFCH.

HACKING, I. 1975. Why Does Language Matter to Philosophy? Cambridge: The University Press.

HACKER, P. M. S. 1981. The Rise and Fall of the Picture Theory. In: BLOCK, I. (ed.) Perspectives on the Philosophy of Wittgenstein. Oxford: Basil Blackwell.

KOJÈVE, A. 1947. Introduction à la lecture de Hegel: Leçons sur la Phénoménologie de L'Esprit. Paris: Ed. Gallimard. 
LACAN, J. 1932. (1975) De la psychose paranoïaque dans ces rapports avec la personnalité. Paris: Ed. du Seuil.

.1945. (1966) Le temps logique et la assertion de certitude

antecipé. Un sofisme. In: Écrits. Paris: Ed. du Seuil.

. 1949. (1966) Le stade du miroir comme formateur de la

fonction du Je, telle qu'elle nous est révélée dans l'expérience

analytique. In: . Écrits. Paris: Ed. du Seuil.

. 1954. (1975) Le Séminaire. Les Ecrits techniques de Freud (1953-

1954), tome 1. Paris: Ed. du Seuil.

du Seuil.

. 1957. (1998) Le Séminaire, tome 4: La relation d'objet. Paris: Ed.

.1960. (1966) Subversion du sujet et dialéctique du désir dans

l'inconscient freudien. In: Écrits. Paris: Ed. du Seuil, 1966.

— 1961. Le Séminaire IX: L'identification. Seminário inédito.

_ 1963. (2004) Le Séminaire, tome 10: L'angoisse. Paris: Ed. du

Seuil.

. 1964a. (1966) Position de l'inconscient au congrès de

Bonneval, reprise de 1960 en 1964. In: Écrits. Paris: Ed. du Seuil.

. 1964b. (1973) Le Séminaire, tome 11 : Les Quatre Concepts

fondamentaux de la psychanalyse. Paris: Ed. du Seuil.

In: Écrits. Paris: Ed. du Seuil.

. 1964c. (1966) Du Trieb de Freud et du désir du psychanalyste. .1969. D’un Autre à l'autre. Seminário inédito.

. 1970. (1991) Le Séminaire, livre XVII, L'envers de la psychanalyse.

Paris: Ed. du Seuil.

. 1971. Le Séminaire XIX : Le savoir de l'analyste / ... Ou pire.

Seminário inédito.

. 1972. (1975 ) Le Séminaire, livre XX, Encore. Paris: Ed. du Seuil. 
. 1974. (2001) La troisième. In: Autres écrits. Paris: Ed. du Seuil.

LYNCH, R. 2001. Mutual Recognition and the Dialectic of Master and Slave: Reading Hegel against Kojève. In: International Philosophical Quarterly, New York, v. XLI, n. 161, p. 33-48.

MORENO, A. R. 1995. Wittgenstein: através das imagens. 2a ed. Campinas: Ed. da Unicamp.

NOBUS, D. 2003. Lacan's science of the subject: between linguistics and topology. In: RABATÉ, J.-M. (ed). The Cambridge Companion to Lacan. Cambridge: The University Press.

POLITZER, G. 1928. (1967) Critiques des fondements de la psychologie, la psychologie et la psychanalyse. Paris: Presses Universitaires de France.

SOLER, C. 2003. The Paradoxes of the Symptom in Psychoanalysis.

In: RABATÉ, J.-M. (ed). The Cambridge Companion to Lacan.

Cambridge: The University Press.

STENIUS, E. 1981. The Picture Theory and Wittgenstein's Later Attitude to it. In: BLOCK, I. (ed.) Perspectives on the Philosophy of Wittgenstein. Oxford: Basil Blackwell.

WITTGENSTEIN, L. 1958. Philosophical Investigations. Trad. G. E. M. Anscombe. Oxford: Basil Blackwell. .1967. Zettel. Trad. G. E. M. Anscombe. Oxford: Basil Blackwell. 1998. Culture and Value. Revised edition. Trad. Peter Winch.

Oxford: Basil Blackwell.

ZIZEK, S. 1991. O Mais Sublime dos Histéricos, Hegel com Lacan. Trad. Vera Ribeiro. Rio de Janeiro: Jorge Zahar. 